\title{
CATAMARAN MOTION SIMULATION BASED ON MOVING GRID TECHNIQUE
}

Ebrahim Jahanbakhsh

Department of Mechanical Engineering, Sharif University of Technology, Iran.

Roozbeh Panahi

Transportation Research Institute, Iran.

Mohammad Saeed Seif

Department of Mechanical Engineering, Sharif University of Technology, Iran., seif@sharif.edu

Follow this and additional works at: https://jmstt.ntou.edu.tw/journal

Part of the Mechanical Engineering Commons

\section{Recommended Citation}

Jahanbakhsh, Ebrahim; Panahi, Roozbeh; and Seif, Mohammad Saeed (2009) "CATAMARAN MOTION SIMULATION BASED ON MOVING GRID TECHNIQUE," Journal of Marine Science and Technology. Vol. 17: Iss. 2, Article 7.

DOI: $10.51400 / 2709-6998.1967$

Available at: https://jmstt.ntou.edu.tw/journal/vol17/iss2/7

This Research Article is brought to you for free and open access by Journal of Marine Science and Technology. It has been accepted for inclusion in Journal of Marine Science and Technology by an authorized editor of Journal of Marine Science and Technology. 


\title{
CATAMARAN MOTION SIMULATION BASED ON MOVING GRID TECHNIQUE
}

\author{
Ebrahim Jahanbakhsh*, Roozbeh Panahi**, and Mohammad Saeed Seif*
}

Key words: finite volume, body-attached grid, free surface, hydrodynamics, catamaran's motions.

\section{ABSTRACT}

General purpose software is developed to simulate 6-DoF fluid-structure interaction in two-phase viscous flow. It is a VoF-fractional step solver based on the finite-volume discretization which uses a boundary-fitted body-attached hexahedral grid as the motion simulation strategy. As an application, a high-speed planing catamaran is simulated in steady forward motion as well as in turning maneuver. Results are compared with the available data and good qualitative and quantitative agreements are achieved.

Numerical schemes and the solution algorithm of the software are consistent and show a good capability to model highly nonlinear ship motions. It can be further developed to represent a more complete model of vessel hydrodynamics by simulating rudder and propeller systems.

\section{INTRODUCTION}

Numerical simulations are becoming a common way to assess ship performance in early design stages. While model tests are still useful, their inherent drawbacks (time, expense, scale effects) have motivated the use of Computational Fluid Dynamics (CFD) as the best choice in many cases.

Real ship hydrodynamics problem involves a turbulent viscous flow with a complex free surface and also fluid-structure interaction. In practice, such a composite problem is simplified by completely ignoring or approximating the less important phenomena.

The motions of a floating or submerged body is a direct consequence of the flow-induced loads (forces and moments) acting on it, while at the same time such loads are a function of the body movement itself. Therefore, prediction of the flowinduced body motions, especially in the case of a viscous fluid, is a challenging task and requires a coupled solution of the fluid flow and the body motions. Over the past two decades,

Paper submitted 01/30/08; accepted 06/14/08. Author for correspondence: Mohammad Saeed Seif (e-mail: seif@sharif.edu)

*Department of Mechanical Engineering, Sharif University of Technology, Iran.

**Transportation Research Institute, Iran. with changes in the computer power, hydrodynamics motions simulation have been the subject of many studies. Such researches evolved from without motion $(0-\mathrm{DoF})[14,2]$ to restricted motions such as trim or sinkage $[11,13]$ and finally to 6 -DoF motions $[1,22,23,17]$. This paper describes a numerical tool capable of simulating the 6-DoF fluid-structure interaction in a viscous free surface flow. After verification, the tool is applied to a high-speed planing catamaran in steady forward motion with two approaches of variable thrust and constant thrust. Besides, it is used to simulate the turning maneuver with different thruster angle. Results are discussed and the software's performance is represented.

\section{NUMERICAL METHOD}

\section{Governing Equations}

The purpose of timing synchronization is to allow the locally generated spreading signal to synchronize with the one embedded in the received signal. The timing synchronization is usually achieved in two stages: code acquisition and code tracking. The code acquisition is used to bring the timing offset between the received signal and the locally generated spreading signal to within the pull-in range of the code tracking loop, and then the code tracking can be initiated to correct the timing offset.

Here, all of the governing equations and vectors are expressed in the Inertial Reference System (IRS) and for a Control Volume (CV) moving with an arbitrary speed of $\vec{u}_{m}$. In order to capture the interface between two phases, a transport equation is implemented (Volume of Fluid-VoF Method):

$$
\frac{d}{d t} \int_{V} \alpha d V+\int_{A} \alpha \vec{c} \cdot \vec{n} d A=0
$$

where $\alpha$, a scalar between zero and one, is known as volume fraction (volume of one phase in the $\mathrm{CV}$ relative to the volume of its $\mathrm{CV}$ ). $\vec{c}=\vec{u}-\vec{u}_{m}$ is the fluid velocity relative to the boundaries of the CV and $\vec{n}$ is the normal to CV's face vector which points outward. $\mathrm{V}$ and $\mathrm{A}$ also represent volume and area of the $\mathrm{CV}$, respectively.

Solving such an equation results in redistribution of two phases in each CV. Then, an effective phase with variable physical properties is introduced in the whole computational domain as follows: 


$$
\begin{gathered}
\rho_{e f f}=\alpha \rho_{1}+(1-\alpha) \rho_{2} \\
v_{e f f}=\alpha v_{1}+(1-\alpha) v_{2}
\end{gathered}
$$

where subscripts 1 and 2 represent two phases.

Such an effective phase is used to solve the incompressible fluid's main governing equations:

$$
\begin{aligned}
& \frac{d}{d t} \int_{V} \vec{u} d V+\int_{A} \vec{u}(\vec{c} \cdot \vec{n}) d A \\
& =\int_{A} v_{e f f} \vec{\nabla} \vec{u} \cdot \vec{n} d A-\frac{1}{\rho_{\text {eff }}} \int_{A} P \vec{n} d A+\int_{V} \vec{g} d V \\
& \int_{A} \vec{c} \cdot \vec{n} d A=0
\end{aligned}
$$

The total loads acting on the body include a force vector $\vec{F}$ on the body mass center and a moment vector $\vec{M}_{G}$ around it, calculated as follow:

$$
\begin{aligned}
\vec{F} & =\vec{F}_{\text {ext }}+\vec{W}+\vec{F}_{\text {flow }} \\
& =\vec{F}_{\text {ext }}+m \vec{g}+\sum_{j=1}^{n}\left(-P_{j} \vec{n}_{j}+\vec{\tau}_{j}\right) A_{j} \\
\vec{M}_{G} & =\vec{M}_{G-\text { ext }}+\vec{M}_{G-\text { flow }} \\
& =\vec{M}_{G-\text { ext }}+\sum_{j=1}^{n}\left(\vec{r}_{j}-\vec{r}_{G}\right) \times\left(-P_{j} \vec{n}_{j}+\vec{\tau}_{j}\right) A_{j}
\end{aligned}
$$

where $\vec{F}_{\text {flow }}$ and $\vec{M}_{G-\text { flow }}$ are calculated by integrating the fluid's normal and tangential stresses over the body surface. $\vec{F}_{e x t}$ and $\vec{M}_{G-e x t}$ can be used to model any external force or moment as well as propeller, rudder, etc. $\vec{W}=m \vec{g}$ is the body weight. Subscript $\mathrm{j}$ stands for each CV's face defining the body surface. Also, $\vec{r}_{j}$ is the position vector of the CV's face center for all faces defining the body and $\vec{r}_{G}$ is the position vector of the body mass center.

Finally, 6-DoF body movements are estimated by solving the linear and angular momentum equations:

$$
\begin{gathered}
\sum \vec{F}=m \vec{a} \\
\sum \vec{M}_{G}=I_{G} \vec{\alpha}+\vec{\omega} \times I_{G} \vec{\omega}
\end{gathered}
$$

\section{Discretization and Solution Algorithm}

Here, the velocity and the pressure fields are coupled using fractional step method [10]. Over-relaxed and Gamma interpolations are used for the spatial discretization of the convection and the diffusion terms, respectively [9]. One must take into account the presence of high density ratio phases e.g.

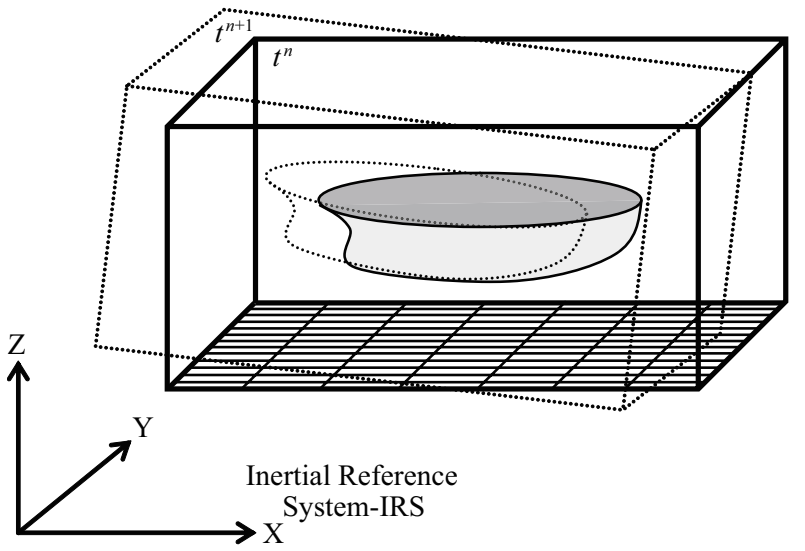

Fig. 1. Schematic view of the computational grid movement during motions in sequential times $\left(t^{n}\right.$ and $\left.t^{n+1}\right)$.

water and air in discretization of the pressure integral. It is treated in a new way. CICSAM interpolation has great advantages in comparison to other interpolations in the case volume fraction transport equation [16] and used for its spatial discretization [21]. Also, the Crank-Nicholson interpolation is used for the temporal discretization of all differential governing equations. More details are available in another paper of the authors to develop a robust interfacial flow solver [8].

There are a wide variety of motion simulation strategies for numerical hydrodynamics applications such as deformable mesh [5], re-mesh [20], sliding mesh [3], overlapping mesh [4], Cartesian mesh [15], etc. Here, a hexahedral boundary-fitted mesh following the time history of body motions (bodyattached grid) is used. Figure 1 shows this strategy (movements of the computational grid as well as the body to prepare the domain for the next time step) in two sequential times.

As mentioned earlier, one encounters to three sub-problems in CFD simulation of hydrodynamics motions. These parts which are marked with dashed lines are solved in a loop as shown in Fig. 2. After a pre-processing (mesh generation and initializing of the parameters), the first sub-problem which includes Navier-Stokes and continuity equations is solved. Output of the first sub-problem (velocity and pressure fields) is used to calculate the total loads acting on the body. It must be mentioned that, although no turbulence model is included; its effect is imposed on the simulation by means of a roughwall approximation [19]. Then, 6-DoF rigid body motion equations are solved in the second sub-problem, which yields to the body movement as well as the computational grid. Two aforementioned sub-problems are solved iteratively in each time step to provide a strongly coupled solution in the whole computational domain (hatched area in Fig. 2). After all, the third sub-problem (volume fraction transport equation) is solved to represent the free surface in the updated grid. Such an algorithm is continued to capture the desired time history. More details are presented in a recent paper by the authors [17]. 


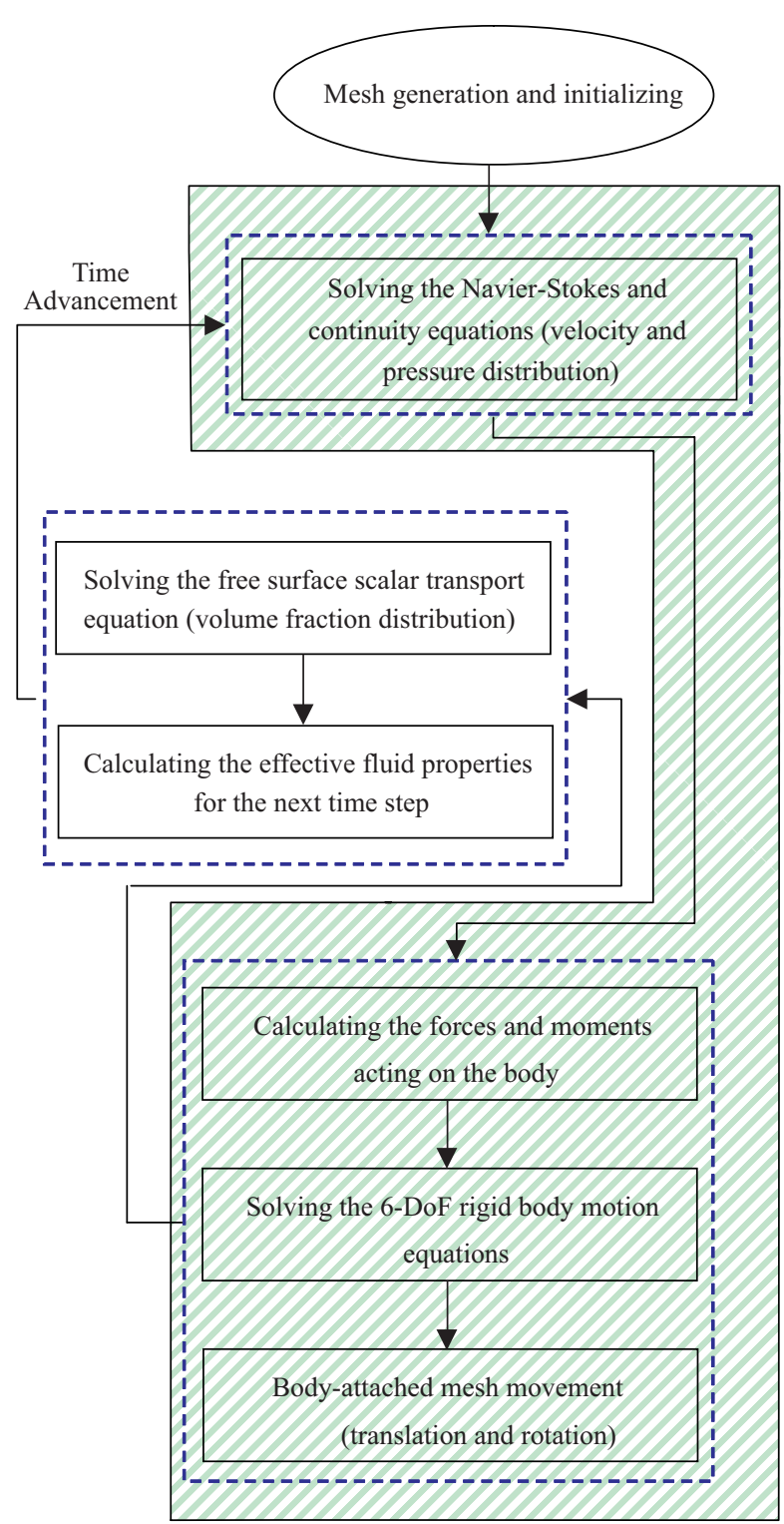

Fig. 2. Solution algorithm in the developed numerical tool.

\section{Verification}

Software is a developed hydrodynamics tool based on the presented algorithm. It is assessed from both accuracy and precision view points. It was necessary to perform a verification analysis for each part of the software as well as its different combinations. The appropriate test cases which are simulated by NUMELS are explained in Table $1[6,18,7]$.

\section{NUMERICAL RESULTS}

Planing catamarans are among the very popular crafts used as a passenger ferry and rescue or patrol boat. Hydrodynamic behavior of such vessels, which includes a considerable variation in heave and pitch due to their hull form produced lift force, is highly nonlinear and put it into the very complicated
Table 1. Validation of the developed software.

\begin{tabular}{|c|c|}
\hline Case & Validation Problem \\
\hline $\begin{array}{l}\text { Velocity-pressure } \\
\text { coupling }\end{array}$ & Orthogonal cavity flow \\
\hline Non-orthogonality & Non-orthogonal cavity flow \\
\hline $\begin{array}{l}\text { Volume fraction } \\
\text { transport equation }\end{array}$ & $\begin{array}{l}\text { Scalar transport in a predefined: } \\
\circ \text { constant oblique velocity field } \\
\circ \text { Shear flow }\end{array}$ \\
\hline Two-phase flow & $\begin{array}{l}\circ \text { Raleigh-Taylor instability } \\
\circ \text { Dam breaking with and without } \\
\text { obstacle } \\
\circ \text { Sloshing in a fixed tank } \\
\end{array}$ \\
\hline $\begin{array}{l}\text { Wave generation and } \\
\text { outlet boundary condition }\end{array}$ & Airy wave generation and transportation \\
\hline $\begin{array}{l}\text { Forced fluid-structure } \\
\text { interaction ( } 0 \text {-DoF) }\end{array}$ & $\begin{array}{ll}\circ & \text { Sloshing in a forced oscillating tank } \\
\circ & \text { Wigley hull resistance } \\
\circ & \text { Cylinder water-exit }\end{array}$ \\
\hline $\begin{array}{l}\text { Free fluid-structure } \\
\text { interaction }(6-\mathrm{DoF})\end{array}$ & $\begin{array}{l}\circ \text { Wedge slamming } \\
\circ \text { Cylinder slamming } \\
\circ \text { Barge resistance and maneuvering } \\
\circ \text { Trimaran resistance and } \\
\text { maneuvering }\end{array}$ \\
\hline
\end{tabular}

Table 2. Catamaran ship characteristics.

\begin{tabular}{|c|c|c|c|}
\hline Characteristic & \multicolumn{3}{|c|}{ Value } \\
\hline Length & $12.3[\mathrm{~m}]$ & & \\
\hline Width & $4.6[\mathrm{~m}]$ & & \\
\hline Draft & $0.95[\mathrm{~m}]$ & & \\
\hline Mass & $17850[\mathrm{~kg}]$ & & \\
\hline Vertical center of gravity & $0.45[\mathrm{~m}]$ & & \\
\hline Longitudinal center of gravity & $3.81[\mathrm{~m}]$ & & \\
\hline $\begin{array}{l}\text { Inertial moment around the } \\
\text { mass center }\end{array}$ & {$\left[\begin{array}{cc}53274 & 0 \\
0 & 295967 \\
0 & 0\end{array}\right.$} & $\begin{array}{c}0 \\
0 \\
325563\end{array}$ & {$\left[\mathrm{~kg} \cdot \mathrm{m}^{2}\right]$} \\
\hline Block coefficient $\left(\mathrm{C}_{\mathrm{B}}\right)$ & $0.33[-]$ & & \\
\hline
\end{tabular}

simulation problems. That is, any numerical simulation is an appreciable step toward replacing the conventional semiexperimental analysis with a more real one in the design procedure.

Here, a high-speed planing catamaran (Fig. 3 and Table 2), is simulated in both steady forward motion and turning maneuver cases. For this study, wide variety of grids (two are shown in Fig. 4) are investigated before deciding on the grid shown in Fig. 5 as the most adequate and appropriate one.

\section{Steady forward motion}

For this case, by considering the symmetry of the problem, a half domain with 95000 hexahedral CVs is used. The thrust force is applied at $0.25 \mathrm{~m}$ above the mass center, with two approaches, namely variable thrust and constant thrust. 


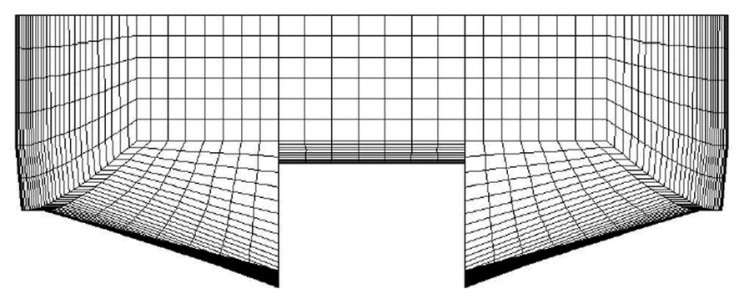

Table 3. Different values of thrust force in the variable thrust approach.

\begin{tabular}{|c|c|c|}
\hline Step & Time interval $(\mathrm{s})$ & Thrust force $(\mathrm{kN})$ \\
\hline 1 & $0.0-47.0$ & 15 \\
\hline 2 & $47.0-90.5$ & 25 \\
\hline 3 & $90.5-105.0$ & 30 \\
\hline 4 & $105.0-192.0$ & 40 \\
\hline 5 & $192.0-230.0$ & 45 \\
\hline 6 & $230.0-262.0$ & 50 \\
\hline
\end{tabular}

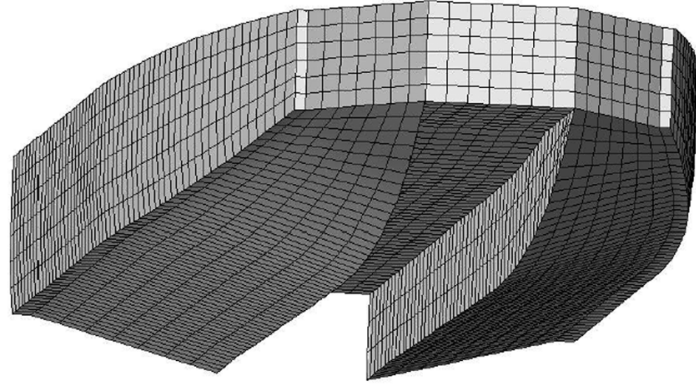

Fig. 3. Catamaran geometry.
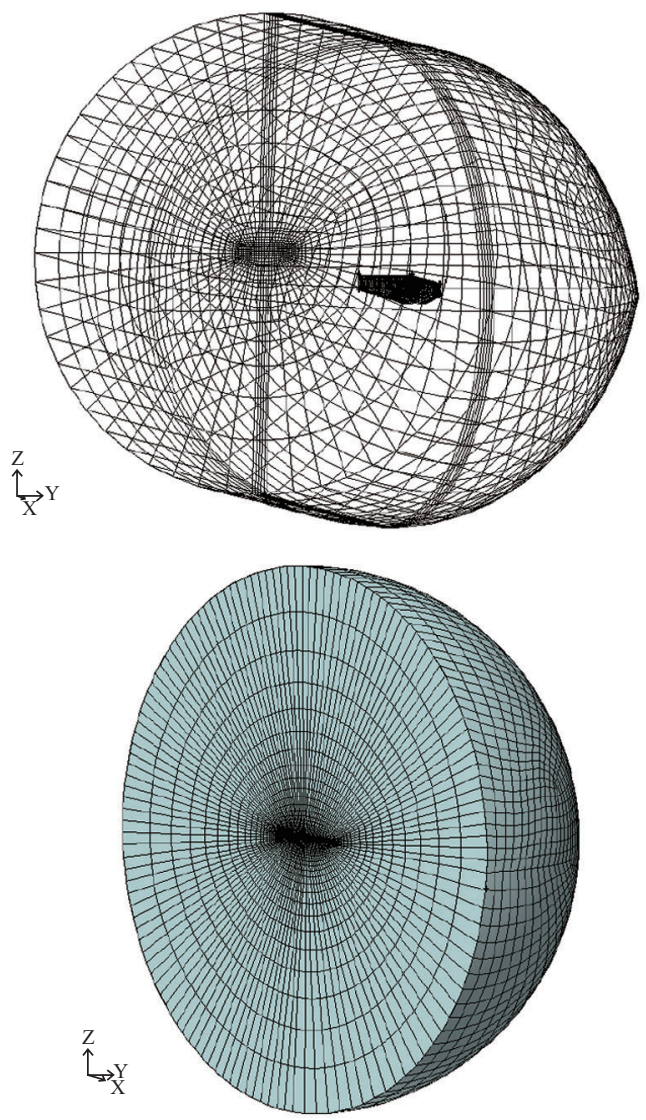

Fig. 4. Different grid alternatives.

In the variable thrust approach, a $15 \mathrm{kN}$ force is initially exerted and stepwise increased whenever an approximately steady behavior is reached. Table 3 shows six steps of thrust

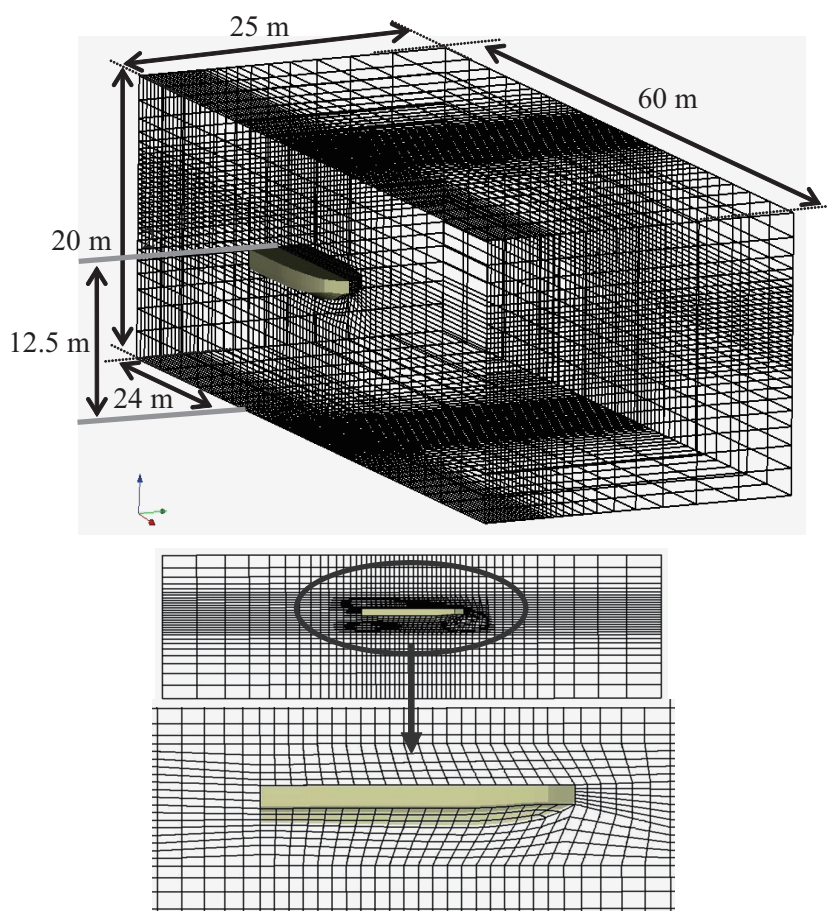

Fig. 5. The computational domain and grid used for catamaran simulation.

change and their applying duration through 262 s of steady forward motion simulation procedure.

Figures 6 to 9 show the time history of the numerical results, using the first approach. Three distinct phases can be distinguished in Fig. 7.

In the first phase $(t=0 \mathrm{~s}$ to $\mathrm{t}=100 \mathrm{~s})$, all diagrams behave smoothly. In this phase, the craft is lifted by $0.2 \mathrm{~m}$ and the trim angle is increased up to $8^{\circ}$. The speed is about $5 \mathrm{~m} / \mathrm{s}$ at the end of this phase and changes a little, except at the initial part of this phase.

In the second phase $(t=100 \mathrm{~s}$ to $\mathrm{t}=250 \mathrm{~s})$, planing starts at the beginning during ten seconds, indicated by the change of the draft (Fig. 7). More accurate description of the planing occurrence is that, its region is somewhere between the first and the second phase and the exact value of the thrust force in the planing point is still not clear according to such a big gap in thrust forces $(30 \mathrm{kN}$ at the end of the first phase and $40 \mathrm{kN}$ at beginning of the second phase). Anyway, the craft is lifted by 


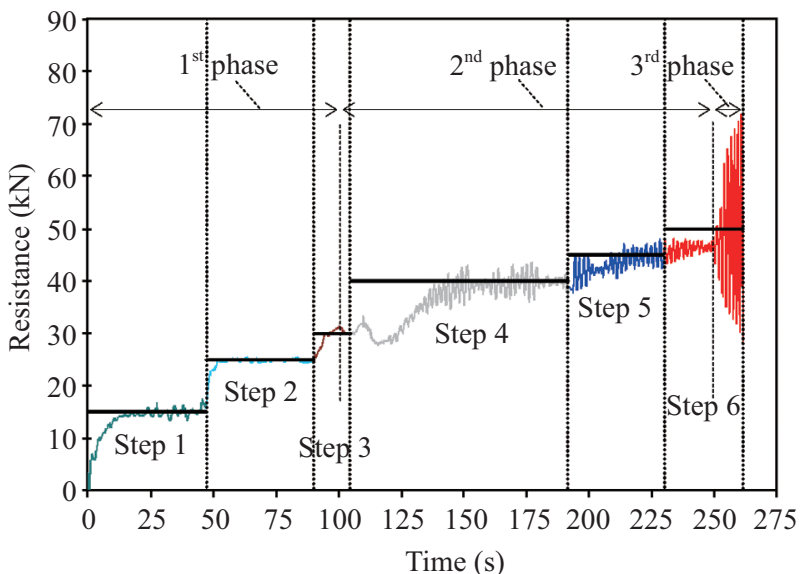

Fig. 6. Resistance time history diagram using the variable thrust approach (Bold lines represent thrust forces).

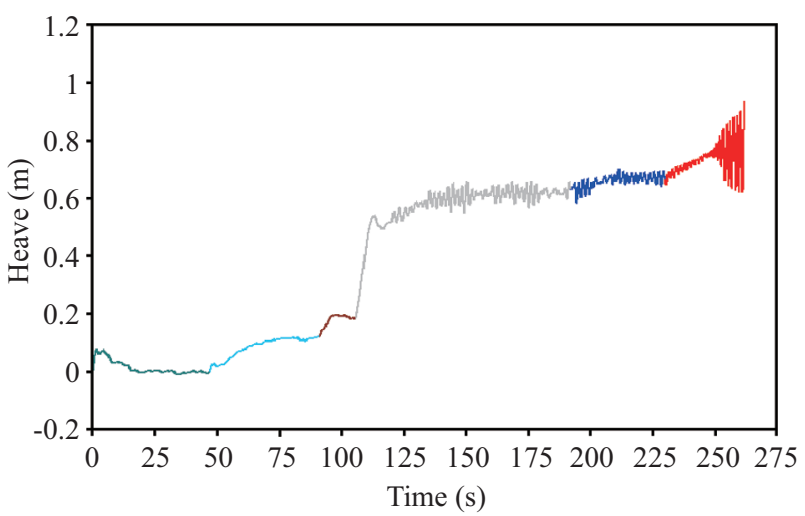

Fig. 7. Draft time history.

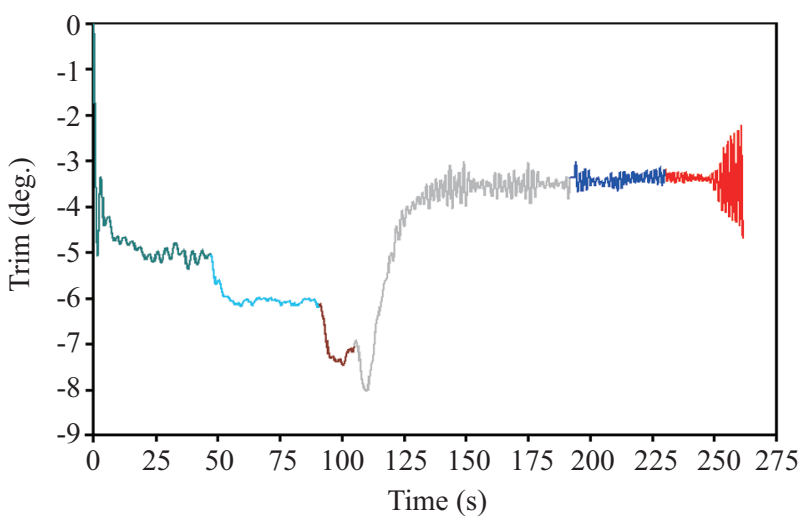

Fig. 8. Trim angle time history.

$0.55 \mathrm{~m}$ (Fig. 7). The trim angle is also decreased from $8^{\circ}$ to $4^{\circ}$ (Fig. 8). The speed is increased abruptly from $5 \mathrm{~m} / \mathrm{s}$ to $25 \mathrm{~m} / \mathrm{s}$ (Fig. 9).

The third phase is accompanied by oscillations in all results with a period of approximately $1.4 \mathrm{~s}$. Here, an unstable dynamical position is obvious at $26 \mathrm{~m} / \mathrm{s}$. This phenomenon accompanied with bow slamming is called porpoising.

Figure 10 shows mean resistance versus speed, extracted from

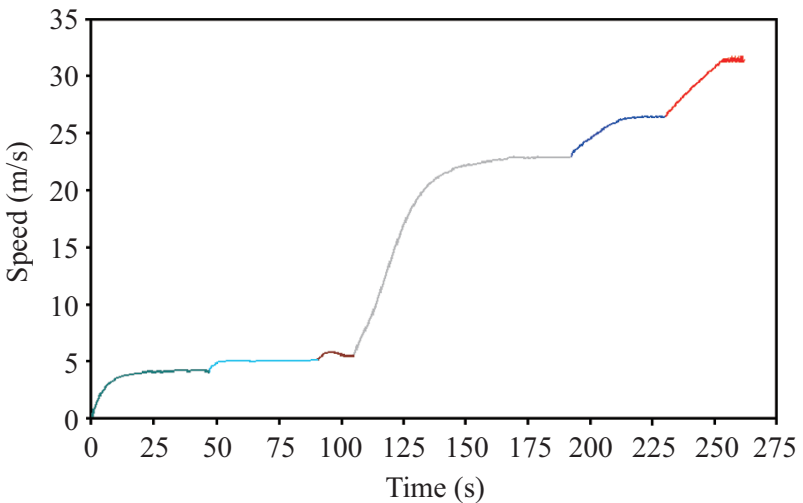

Fig. 9. Speed time history.

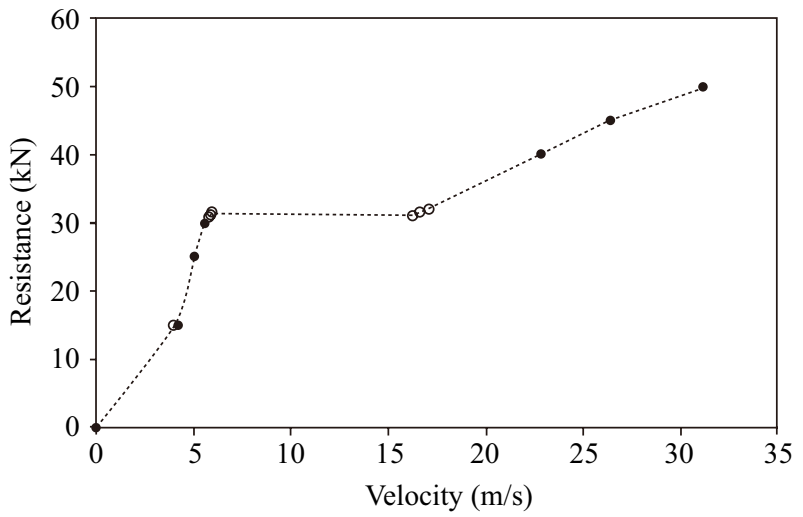

Fig. 10. Mean resistance versus speed.

Figs. 6 and 9 and additional simulations. In other words, only the black points were appeared using such figures (Table 3 thrust force change). Therefore, the lack of data points forced to continue and form the second level of simulations, using further stepwise thrust changes. Such steps were established using the two ends of the currently known planing region (end of the first phase and beginning of the second phase). That is, the simulations were completed between such phases, by increasing and decreasing the thrust force from two points of $30 \mathrm{kN}$ and $40 \mathrm{kN}$, respectively. Such a strategy helped to constrict the planing region sides. Aggregation of the new points (hollow points in Fig. 10) clearly tells about the closer boundaries of the planing region. Actually, it is not possible to continue and give more steady results according to the unsteady characteristic of the updated planing region.

The left part of the results in Fig. 10 belongs to the first motion phase and before the planing occurrence (before planing region). At this part, the resistance experiences an approximately second-order increase versus forward speed. The right part of the results belongs to the second and third motion phases and after planing occurrence (after planing region). Here an approximately first-order increase of the resistance versus forward speed is obvious. The dashed line which connects these two parts of results is an assumption which can be used as an estimate for the planing region. As 


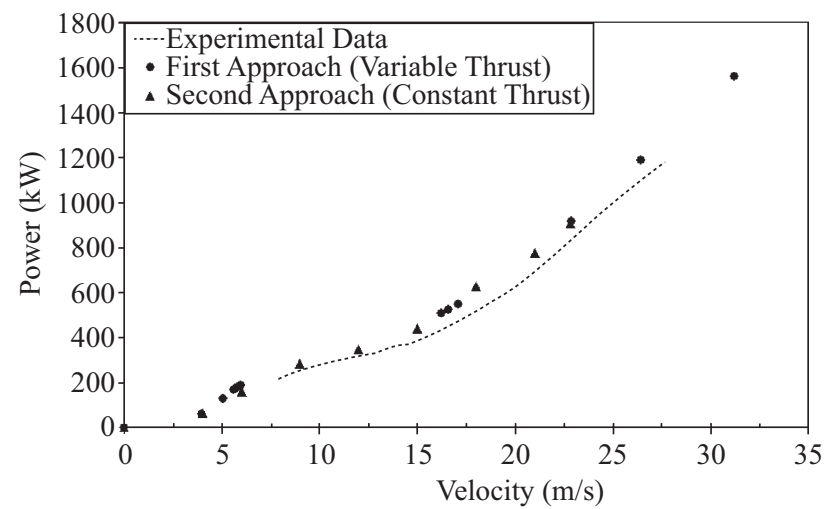

Fig. 11. Computed and experimental power.

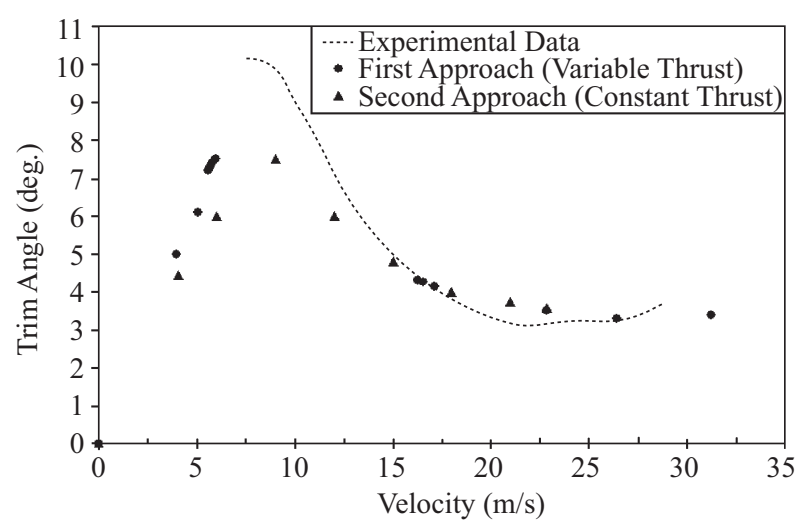

Fig. 12. Computed and experimental trim.

aforementioned, such a gap in the data points is a direct consequence of the unsteady behavior of the craft in such a region.

Figures 11 and 12 compare computed and experimental power and trim, respectively. The lack of data points in the planing region using the first approach (variable thrust), strongly encouraged performing another series of steady forward motion simulation. Therefore, using the constant thrust was nominated as the second approach. Here, the time history of the craft is recorded regardless of reaching a steady behavior by applying a constant thrust of $40 \mathrm{kN}$ all over the simulation procedure. It seems that, the latter approach is the only way to get results in the planing region and to overcome the inability of the former one.

Figure 11 shows that, the second approach (constant thrust) predicts power well for all speeds in contrast to the first approach (variable thrust). Besides, the results of the first and the second approaches are close to each other. These two properties encourage using the second approach which is simpler in practice. The first approach predicts trim better, especially near the maximum value, although there are no computed data points at the maximum itself (Fig. 12).

Figure 13 shows some snap shots of the catamaran in forward motion at different speeds. The depth and the length of the water surface deformation at the stern of the craft increase with speed, while the angle of the generated wave relative to

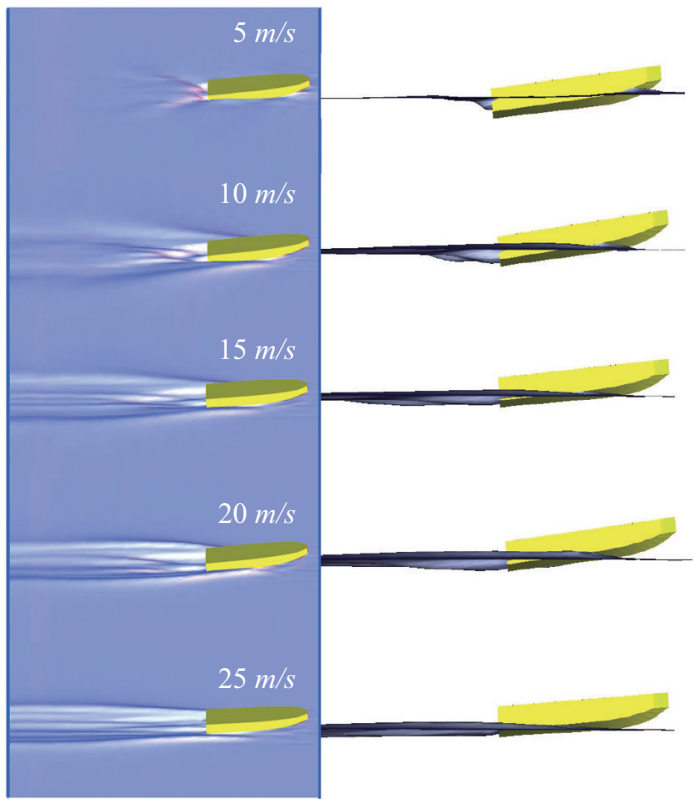

Fig. 13. Snapshots of the catamaran in forward motion at different speeds.
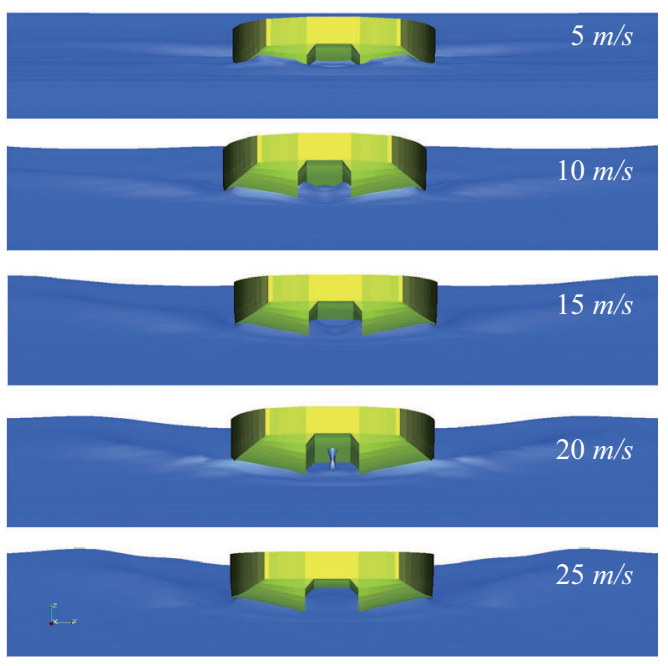

Fig. 14. Front view of the catamaran at different speeds.

the motion direction decreases. The catamaran wet-deck has also different positions relative to the water surface at different speeds. For low speed before planing, the wet-deck becomes wet, but at higher speeds it rises from the water as it is clear from Fig. 14.

\section{Turning Maneuver}

It is a common practice to use the Body-Fixed Coordinate System (BFCS) for description of maneuvering set-up and results. The origin is usually at the mass center, with the $\mathrm{x}$-axis and $\mathrm{y}$-axis positive to bow and port, respectively. The $\mathrm{z}$-axis is also positive upward.

The required maneuvering forces and moments are modeled using two thrusters of the form $\vec{T}=(T \operatorname{Cos} \alpha, T \operatorname{Sin} \alpha, 0)$, 
Table 4. Three steps of turning maneuver simulation.

\begin{tabular}{|c|c|c|c|c|c|c|}
\hline & & \multicolumn{5}{|c|}{ Set-up for the craft with two thrusters } \\
\hline Step of simulation & Step description & $\begin{array}{c}\text { Forward speed } \\
\qquad(\mathrm{m} / \mathrm{s})\end{array}$ & $\begin{array}{c}\text { Thruster magnitude } \\
\mathrm{T}(k N)\end{array}$ & $\begin{array}{l}\text { Thruster } \\
\text { angle (deg.) }\end{array}$ & Number of DoF & Duration $(s)$ \\
\hline 1 & $\begin{array}{l}\text { Advance with } \\
\text { forward speed }\end{array}$ & 10 & - & - & $\begin{array}{c}2 \\
\text { (Heave, Pitch) }\end{array}$ & 10 \\
\hline 2 & $\begin{array}{l}\text { Advance with } \\
\text { forward thruster }\end{array}$ & - & 14.5 & 0 & $\begin{array}{c}3 \\
\text { (Surge, Heave, Pitch) }\end{array}$ & 5 \\
\hline \multicolumn{7}{|c|}{ Turning maneuver starting point at $\mathrm{t}=15 \mathrm{~s}$ or $(10+5) \mathrm{s}$} \\
\hline 3 & Turning maneuver & - & 14.5 & $\alpha$ & 6 & - \\
\hline
\end{tabular}

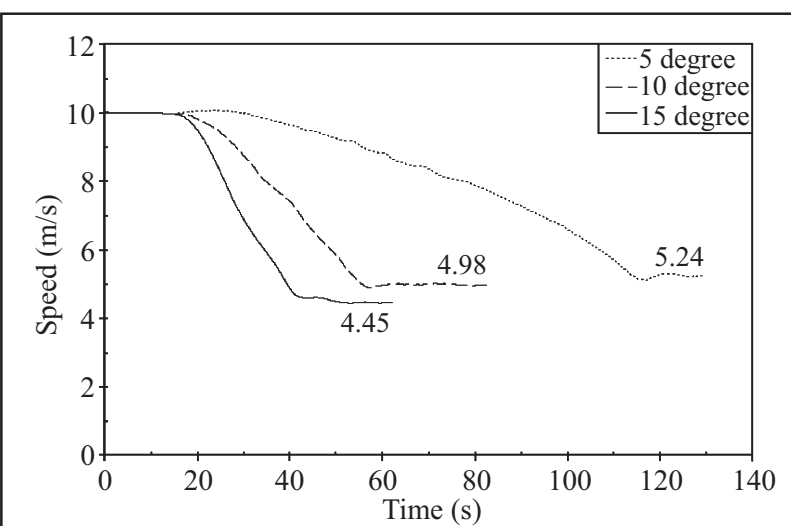

(a)
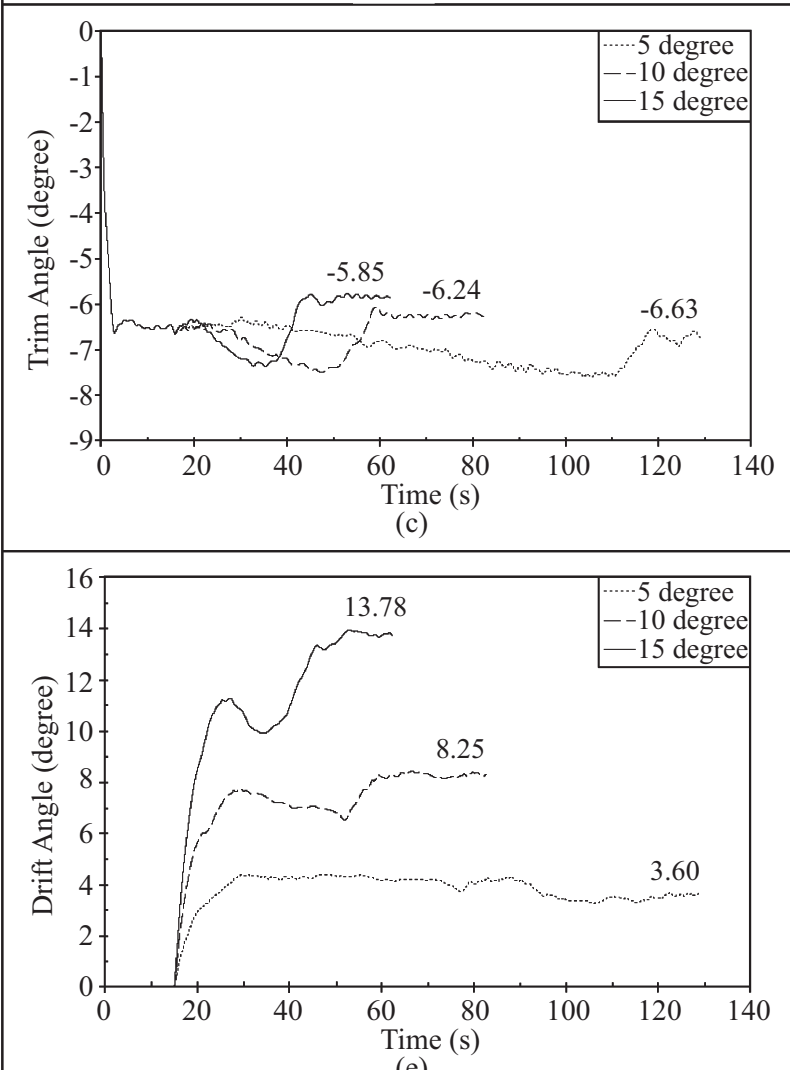

(e)

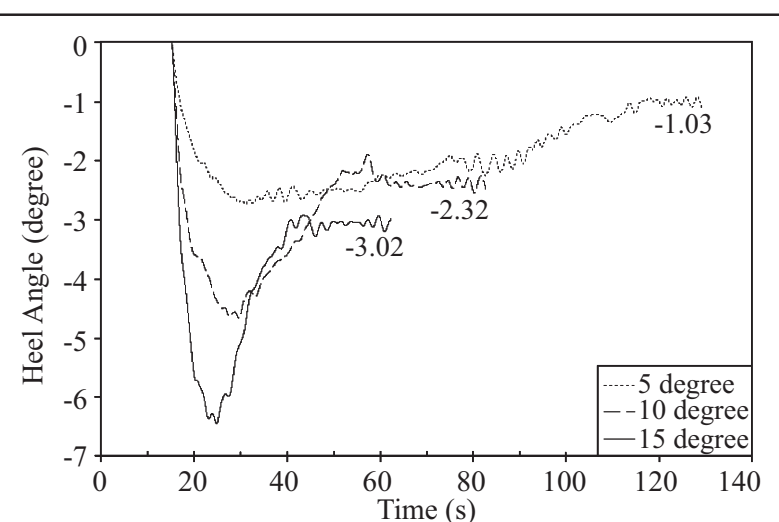

(b)



(d)

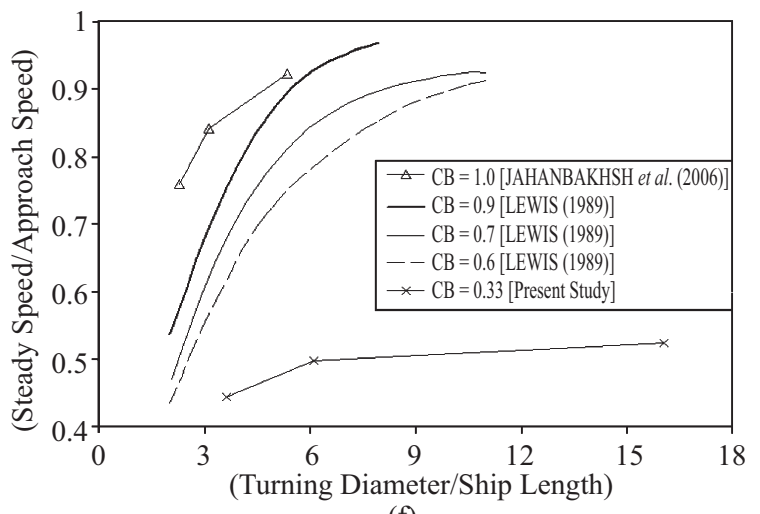

(f)

Fig. 15. Catamaran turning maneuver; (a) speed time history, (b) heel angle time history, (c) trim angle time history, (d) yaw angle time history, (e) drift angle time history, (f) speed reduction factor. 


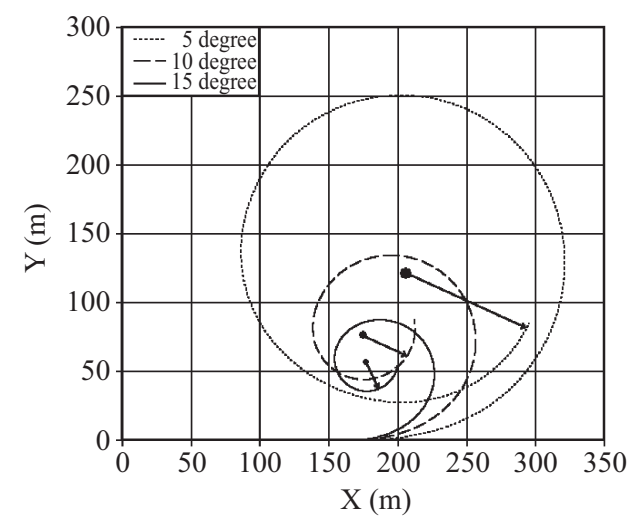

(a)



(b)

Fig. 16. Path of the catamaran during turning maneuver; (a) turning path and the center of steady turning circle, (b) overshoot just after the starting point.

where $\mathrm{T}$ is the thruster magnitude and $\alpha$ is the thruster angle which is the smaller angle between the thruster direction and the $\mathrm{x}$-axis of BFCS. Therefore, $\alpha$ is considered as the angle of the thruster's shaft whish is possible for the most surface derives of high-speed crafts. Such thrusters were exerted at points $R_{1}$ and $R_{2}$ as below:

$$
R_{1}=(-4.5,1.5,0.25) ; R_{2}=(-4.5,-1.5,025)
$$

The full domain of 190000 hexahedral CVs is used as a computational grid. Here, the turning maneuver is investigated for $5^{\circ}, 10^{\circ}$ and $15^{\circ}$ thruster angles. The simulation procedure for each angle included three steps applied stepwise (Table 4). Therefore, all of the turning maneuver simulations begin with the same conditions (approach speed of $10 \mathrm{~m} / \mathrm{s}$ and two thrusters of $14.5 \mathrm{kN}$ ) at the third step and the only difference is the angle.

Simulations showed that, after experiencing approximately similar trends in parameters' variations (Fig. 15), all cases reached a steady turning (turning on a circle with a constant radius) (Fig. 16 and Table 5). That is, the total duration for the craft to be on a constant circle from the beginning of the turning (starting point), is equivalent to that of representing approximately steady characteristics in displacements, speeds and accelerations. Such a duration increases in the case of smaller thruster angle (Fig. 15). In other words, duration of the craft's transient phase is an inverse function of the thruster angle.
Table 5. Catamaran turning maneuvering data.

\begin{tabular}{|c|c|c|c|}
\hline $\begin{array}{c}\text { Thruster angle } \\
(\text { deg. })\end{array}$ & $\begin{array}{c}\text { Radius of } \\
\text { the turning } \\
\text { circle }(m)\end{array}$ & $\begin{array}{c}\text { Center of the } \\
\text { turning Circle }(m)\end{array}$ & $\begin{array}{c}\text { Duration of the } \\
\text { transient phase } \\
(s)\end{array}$ \\
\hline 5 & 98.72 & $(205.84,121.23)$ & 102 \\
\hline 10 & 37.55 & $(174.88,76.21)$ & 31 \\
\hline 15 & 22.24 & $(177.19,56.65)$ & 28 \\
\hline
\end{tabular}

Speed of the craft decreases just after the beginning of the turning, with different slopes in each thruster angle (Fig. 15(a)). The final turning speed (steady speed) of the craft is higher in the case of lower thruster angle, although there is just a little difference between all steady speeds. It must be remembered that, the ability of a craft to keep its approach speed in different turning circles is evaluated by a parameter called speed reduction factor (steady speed/approach speed). The craft's speed reduction factor is plotted in Fig. 15(f) in comparison to the other block coefficients. Actually, repeating the simulation procedure for a constant $\mathrm{CB}$ and different geometries, results in selecting the best body form, from the speed reduction factor view point.

The heel angle of the craft is always negative and has a minimum just after the starting point, as was expected from the experiments about the high-speed vessels (Fig. 15(b)). The steady heel angle also increases as the thruster angle decreases.

The trim angle variation includes a smooth decreasing just after the starting point, reaching to a minimum value and then increasing up to represent a steady trim angle (Fig. 15(c)). Besides, Figs. 8 and 9 show that, the craft's trim angle decreases until reaching to the planing region, represents a minimum and then increases until going to an approximately straight line. Taking into account that the approach velocity of the craft $(10 \mathrm{~m} / \mathrm{s})$ put it a bit after the planing region and also, the turning yields to a reduction in the craft's speed (here, moves it to the before planing region), such a trend in the trim angle diagram (Fig. 15(c)) is a reasonable behavior.

The yaw angular velocity behave a bit different as it is shown in Fig. 15(d). It has a maximum and then a minimum just after the starting point to reach a steady value in $10^{\circ}$ and $15^{\circ}$ thruster angles. But, it behaves approximately smooth in the case of $5^{\circ}$ thruster angle. Regardless of such behaviors, the steady yaw angular velocity decreases as well as the thruster angle in all cases. It is obvious form Fig. 15(e) that the drift angle, the difference between the craft and speed direction, behaves similar to the yaw angular velocity. It must remembered that, the craft is free in all 6-DoF and it is possible to represent all other results.

The path of the craft, center of the steady turning circle and overshoot of the craft are plotted in Fig. 16 for different thruster angles. It is obvious that the overshoot increases as a direct function of the thruster angle. The difference between the steady turning radiuses of $5^{\circ}$ and $10^{\circ}$ thruster angles is very larger than that of $10^{\circ}$ and $15^{\circ}$ as given in Table 5. This results 


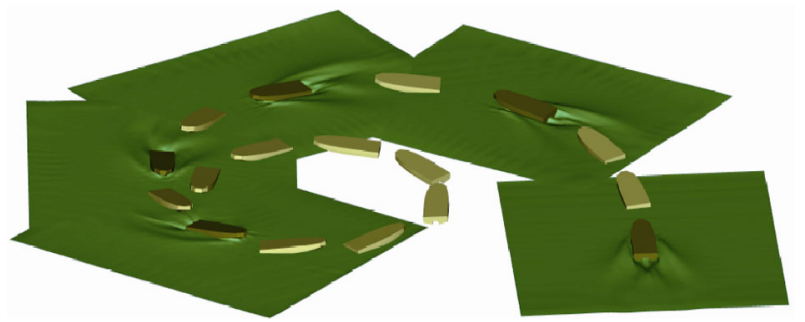

Fig. 17. Snapshots of the catamaran during the turning maneuver with thruster angle of $10^{\circ}$.

in much longer time to have a steady turning at $5^{\circ}$ in contrast to $10^{\circ}$ and $15^{\circ}$ (Table 5). Figure 17 shows snapshots of the craft turning with thruster angle of $10^{\circ}$.

\section{CONCLUSION}

High-speed planing crafts have very complicated hull shape and their motions contain strong nonlinearity. The only simulation tool for such cases is CFD modeling. In this paper, development of a numerical tool based on $\mathrm{VoF}$-fractional step flow solver for an effective incompressible viscous fluid and the boundary-fitted body-attached grid as the motion simulation strategy is described and its validation procedure is explained in brief.

The software is successfully used for steady forward and turning motion of a high-speed planing catamaran. Numerical results have good concordance with available experimental data. The algorithm and the software show good capabilities for simulation of such complex hydrodynamics problems.

\section{REFERENCES}

1. Azcueta, R., Computation of Turbulent Free Surface Flow Around Ships and Floating Bodies, $\mathrm{PhD}$ Thesis, Teschnichen Universitat HamburgHarburg. (2001).

2. Allessandrini, B. and Delhommeau, G., "Simulation of three-dimensional unsteady viscous free surface flow around a ship model," International Journal of Numerical Methods in Fluids, Vol. 19, pp. 321-342 (1994).

3. Blades, E. and Marcum D. L., "A sliding interface method for unsteady unstructured flow simulations," International Journal of Numerical Methods in Fluids, Vol. 53, pp. 507-529 (2007).

4. Carrica, P. M., Wilson, R. V., Noack, R. W., and Stern, F., "Ship motions using single-phase level set with dynamic overset grids," Computers \& Fluids, Vol. 36, No. 9, pp. 1415-1433 (2007).

5. Chentanez, N., Goktekin, T. G., Feldman, B. E., and O'brien, J. F., "Simultaneous coupling of fluids and deformable bodies," Proceeding of
ACM SIGGRAPH/Eurographics Symposium on Computer Animation, Vienna, pp. 83-89 (2006).

6. Jahanbakhsh, E., Panahi, R., and Seif, M. S., "Multi-dimensional free surface flow simulation using two-phase Navier-Stokes solver," Proceeding of 8th Numerical Towing Tank Symposium (NuTTS), Varna (2005).

7. Jahanbakhsh, E., Panahi, R., and Seif, M. S., "Ship dynamic simulation based on a three-dimensional viscous free surface solver," Proceeding of 9th Numerical Towing Tank Symposium (NuTTS), Le Croisic (2006).

8. Jahanbakhsh, E., Panahi, R., and Seif, M. S., "Numerical simulation of three-dimensional interfacial flows," International Journal of Numerical Methods for Heat \& Fluid Flow, Vol. 17, No. 4, pp. 384-404 (2007).

9. Jasak, H., Error Analysis and Estimation for Finite Volume Method with Application to Fluid Flows, PhD Thesis, University of London (1996).

10. Kim, D. and Choi, H., "A second-order time-accurate finite volume method for unsteady incompressible flow on hybrid unstructured grids," Journal of Computational Physics, Vol. 162, pp. 411-428 (2000).

11. Kinoshita, T., Kagemoto, H., and Fujino, M., "A CFD application to wave-induced floating-body dynamics," Proceeding of 7th International Conference on Numerical Ship Hydrodynamics, Nantes, France (1999).

12. Lewis, E., Principle of Naval Architecture, Second Revision, Vol. III, The Society of Naval Architectures and Marine Engineering (1989).

13. Miyake, R., Kinoshita, T., and Kagemoto, H., "Ship Motions and loads in large waves," Proceeding of 23rd ONR Symposium On Naval Hydrodynamics, Val de Reuil, France (2000).

14. Miyata, H., Sato, T., and Babo, N., "Difference solution of a viscous flow with free-surface wave about an advancing ship," Journal of Computational Physics, Vol. 72, pp. 393-421 (1987).

15. Mital, M. and Iccarino, G., "Immersed boundary methods," Annual Review of Fluid Mechanics, Vol. 37, pp. 239-261 (2005).

16. Panahi, R., Jahanbakhsh, E., and Seif, M. S., "Comparison of interface capturing methods in two phase flow," Iranian Journal of Science \& Technology, Transaction B: Technology, Vol. 29, No. B6 (2005).

17. Panahi, R., Jahanbakhsh, E., and Seif, M. S., "Development of a VoF fractional step solver for floating body motion simulation," Applied Ocean Research, Vol. 28, No. 3, pp. 171-181 (2006).

18. Panahi, R., Jahanbakhsh, E., and Seif, M. S., "Development of a numerical hydrodynamic tank for ship motion simulation," Proceeding of European Congress on Computational Methods in Applied Sciences and Engineering, Egmond aan Zee (2006).

19. Schlichting, H, Boundary-layer theory, 7th ed., McGraw-Hill (1979).

20. Tremel, U., Sorensen, K. A., Hitzel, S., Rieger, H., Hassan, O., and Weatherill, N. P., "Parallel remeshing of unstructured volume grids for CFD applications," International Journal of Numerical Methods in Fluids, Vol. 53, pp. 1361-1379. (2007).

21. Ubbink, O. and Issa, R. I., "A method for capturing sharp fluid interfaces on arbitrary meshes," Journal of Computational Physics, Vol. 153, pp. 26-50 (1999).

22. Vogt, M. and Hochbaum, C., "Numerical simulation of ship motions in head waves with a RANSE method," HSVA Report 1649, Hamburg, Germany (2002).

23. Xing-Kaeding, Y., Unified Approach to Ship Seakeeping and Maneuvering by a RANSE Method, $\mathrm{PhD}$ Thesis, Teschnichen Universitat Hamburg-Harburg (2004). 